\title{
Oxidative Phosphorylation: A Target for Novel Therapeutic Strategies Against Ovarian Cancer
}

\author{
Amruta P. Nayak ${ }^{1,2}$, Arvinder Kapur ${ }^{2}$, Lisa Barroilhet ${ }^{2}$ and Manish S. Patankar ${ }^{2, *(1)}$ \\ 1 Indian Institute of Science Education and Research, Pune 411008, India; amruta.pn@students.iiserpune.ac.in \\ 2 Department of Obstetrics and Gynecology, University of Wisconsin-Madison, Madison, WI 54911, USA; \\ akaur@wisc.edu (A.K.); barroilhet@wisc.edu (L.B.) \\ * Correspondence: patankar@wisc.edu; Tel.: +1-608-262-8871
}

Received: 25 July 2018; Accepted: 17 September 2018; Published: 18 September 2018

\begin{abstract}
Aerobic glycolysis is an important metabolic adaptation of cancer cells. There is growing evidence that oxidative phosphorylation is also an active metabolic pathway in many tumors, including in high grade serous ovarian cancer. Metastasized ovarian tumors use fatty acids for their energy needs. There is also evidence of ovarian cancer stem cells privileging oxidative phosphorylation (OXPHOS) for their metabolic needs. Metformin and thiazolidinediones such as rosiglitazone restrict tumor growth by inhibiting specific steps in the mitochondrial electron transport chain. These observations suggest that strategies to interfere with oxidative phosphorylation should be considered for the treatment of ovarian tumors. Here, we review the literature that supports this hypothesis and describe potential agents and critical control points in the oxidative phosphorylation pathway that can be targeted using small molecule agents. In this review, we also discuss potential barriers that can reduce the efficacy of the inhibitors of oxidative phosphorylation.
\end{abstract}

Keywords: high grade serous ovarian cancer; metabolism; mitochondria; oxidative phosphorylation; oxidative stress; biguanides; atovaquone; plumbagin; thiazolidinediones; ubiquinone; Nrf-2

\section{Introduction}

Metabolic adaptations allow tumors to maintain a highly proliferative state. Evidence in support of such adaptations was obtained nearly a century ago by Otto Warburg, and Carl and Gert Cori and their colleagues when they demonstrated an increased uptake of glucose by tumors as compared to normal tissues [1,2]. Warburg further demonstrated that even when sufficient oxygen was available, tumors used glycolysis to metabolize glucose to lactic acid [3,4]. In this respect, glucose metabolism in tumor cells resembles that occurring under anaerobic conditions. However, because glucose was being metabolized to lactate in the presence of oxygen, Warburg coined the term "aerobic glycolysis" to accurately describe this metabolic process in tumors [3]. Although glucose breakdown through oxidative phosphorylation (OXPHOS) yields maximum number of ATP, curtailing the metabolism to glycolysis provides the necessary biomolecule precursors needed by the tumors to maintain a high level of proliferation [5-8]. Several key enzymes in the glycolytic pathway and tricarboxylic acid cycle, (pyruvate kinase M2, pyruvate dehydrogenase kinase, isocitrate dehydrogenase, succinate dehydrogenase, lactate dehydrogenase and others (representative articles include [9-17]) are targets for anti-cancer drugs.

A rapidly growing body of evidence is demonstrating that an adaptation to aerobic glycolysis does not entail a complete shutdown of oxidative phosphorylation (OXPHOS) in tumors. Active electron transport occurs in cancer cells that trigger tumor recurrence and in cancer stem cells [18-20]. Here, we review evidence supporting the importance of OXPHOS in high grade serous ovarian cancer (HGSOC), 
discuss small molecule inhibitors of OXPHOS, their mechanism of action, and potential barriers to the use of such agents for the treatment of HGSOC.

\section{Oxphos As Target for Hgsoc Therapy}

Ovarian cancer is classified into type I and II diseases [21-23]. Clear cell cancer and low grade endometrioid are major types of ovarian tumors classified as Type I malignancies with mutations in ARID1A (AT-rich interactive domain-containing protein 1A), K-Ras (Kirsten rat sarcoma) and PTEN (phosphatase and tensin homolog). High grade serous ovarian cancer (HGSOC), the predominant subtype, is classified as Type II disease and is characterized by mutations in p53 and copy number variations [24-29]. In the majority of the patients, HGSOC is detected at an advanced stage when the tumor has progressed to sites beyond the ovaries. While cytoreductive surgery and chemotherapy with platinum and taxanes are initially effective, they fail to prevent recurrence of HGSOC. Recurrent HGSOC responds poorly to most established and experimental therapies. While PARP (ADP ribose polymerase) inhibitors have extended overall survival [30-33], there remains a need for additional novel therapeutic approaches to treat HGSOC. In this review, we make the case that OXPHOS be considered as a druggable pathway while developing novel therapies against HGSOC.

In normal cells, glucose is metabolized through glycolysis, tricarboxylic acid cycle and OXPHOS to produce 34-38 molecules of ATP per molecule of glucose (Figure 1). In cancer and other highly proliferative and activated cells (immune cells, for example), the end product of glycolysis, pyruvate, is not transferred to the mitochondria and consumed in the tricarboxylic acid cycle, but instead is converted to lactate (Figure 1). This conversion to lactate allows the cells to regenerate NAD (Nicotinamide Adenosine Dinucleotide) needed to drive the conversion of glyceraldehyde-3-phosphate to 1,3-bisphosphoglycerate in glycolysis.

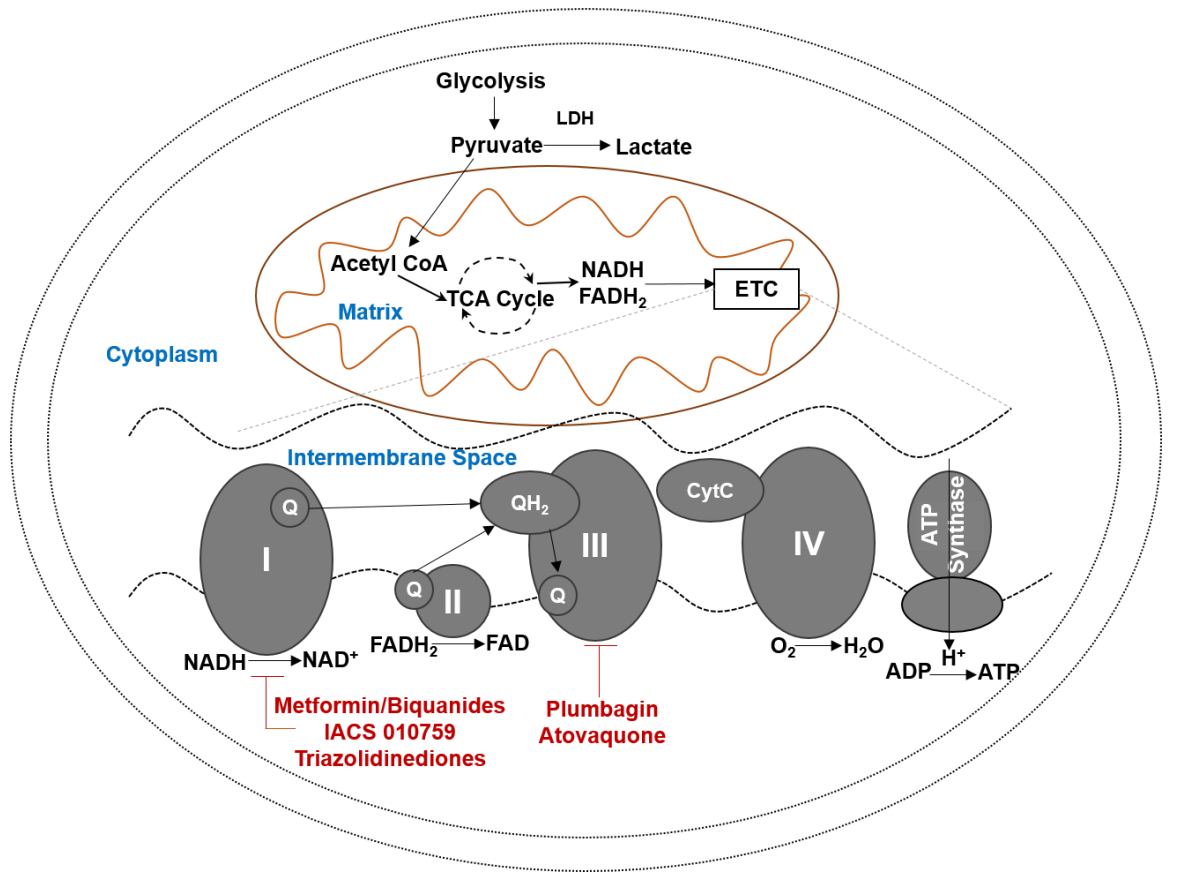

Figure 1. Oxidative phosphorylation. Aerobic glycolysis metabolizes glucose to lactic acid. Oxidative phosphorylation (OXPHOS) occurs in mitochondria and leads to efficient generation of ATP. OXPHOS is an active pathway in tumors and cancer stem cells. Several inhibitors or the various subunits of the mitochondrial electron transport complexes can serve as candidates for tumor therapy. Prominent drug candidates for HGSOC are shown. CytC, Cytochrome C, ETC, Electron Transport Chain, LDH, Lactate Dehydrogenase, Q, unbiquinone, QH2, Ubiquinol, TCA, Tricarboxylic Acid Cycle, $\mathrm{FADH}_{2}$, Flavine Adenine Dinucleotide, NADH, Nicotinamide Adenine Dinucleotide. 
An active glycolytic pathway supplies the biochemical precursors required for protein, nucleotide and lipid synthesis. This is an important reason why cancer cells limit glucose metabolism to glycolysis even when there is sufficient availability of oxygen. Ovarian tumors also show metabolic adaptation to aerobic glycolysis that allows them to maintain an increased proliferative capacity and survive under anchorage dependent conditions [34-36]. Adaptation of the ovarian cancer cells to aerobic glycolysis is supported by the increased expression of the glycolytic enzymes pyruvate kinase isoform M2 (PKM2), hexokinase II, and lactate dehydrogenase A (LDHA). PKM2 catalyzes the conversion of phosphoenolpyruvate to pyruvate and regulates the flux of acetyl coA available to enter the tricarboxylic aid cycle. Elevated expression of PKM2 correlates with decreased progression free survival in HGSOC although overall survival is not affected [37]. Hexokinase II is also upregulated in HGSOC $[38,39]$. Elevated hexokinase II expression contributes to chemoresistance in ovarian tumors [40].

The metabolic shift to aerobic glycolysis provides the precursors for synthesis of proteins, nucleotides and lipids, at the expense of ATP. To compensate, cancer cells overexpress glucose transporters. As a result, there is an increased uptake of glucose that is catabolized through aerobic glycolysis. Serous ovarian tumors express high levels of glucose transporters GLUT1, GLUT3 and GLUT4, as compared to healthy and benign ovarian tissues [41,42]. Increased uptake of glucose through the upregulation of glucose transporters (GLUT) is a hallmark of HGSOC allowing their imaging by 18-fluoro-deoxyglucose positron emission tomography (FDG-PET) [43,44].

The molecular mechanisms responsible for the metabolic reprogramming in cancer are under investigation. One mechanism is through the regulation of pyruvate kinase M2 isoform (PKM2) activity through its interactions with growth factor receptors [45]. There is emerging evidence that mutated BRCA1 [46] and mutated p53 (reviewed in [47]), two genes that are most frequently mutated in HGSOC, also contribute to the shift to aerobic glycolysis. In HGSOC, the sulfatase, h-Sulf-1 is downregulated [48]. Loss of h-sulf- 1 in HGSOC increases glycolytic activity through the phosphorylation of pyruvate dehydrogenase causing a decrease in availability of pyruvate in the tricarboxylic acid cycle [49]. All of these results clearly demonstrate that glycolysis is a major metabolic adaptation occurring in HGSOC.

\subsection{Relevance of OXPHOS in Solid Tumors}

While aerobic glycolysis is an important adaptation in HGSOC, OXPHOS is also an active pathway in cancer cells [50-56]. Initial data in support of this observation was gained from experiments with the tetracycline-inducible K-Ras (G12D) mouse model for pancreatic cancer [57]. Withdrawal of doxycycline caused regression of the pancreatic ductal carcinomas [55]. However, tumor recurrence was observed in the mice 4-5 months after doxycycline withdrawal. Tumor relapse was attributed to cancer stem cells surviving the ablation of mutant K-Ras. These surviving cancer stem cells had increased mitochondrial biogenesis with higher OXPHOS activity but impaired glycolysis. The relapsing tumors were responsive to the OXPHOS inhibitor, oligomycin [55].

Tumor cells that utilize aerobic glycolysis, coexist with cancer cells with active OXPHOS. A recent report by Yu et al [58] developed a model to predict the predominant metabolic pathway utilized by normal and cancer cells. Glycolysis is indicated by high expression of HIF- $1 \alpha$ (Hypoxia inducible factor- $1 \alpha$ ) and low levels of phospho- $5^{\prime}$ AMP-activated protein kinase (pAMPK), whereas OXPHOS-reliant tumors have low levels of HIF- $1 \alpha$ and high levels of pAMPK. Some cancer cells express high levels of both HIF- $1 \alpha$ and pAMPK indicating active glycolysis as well as OXPHOS.

There are, however, some indicators that active mitochondrial metabolism may have a favorable outcome. The Bioenergetic Cellular (BEC) index, a ratio $\beta$-F1ATPase (F1 portion of adenosine triphosphate synthase) to HSP60 (Heat Shock Protein 60) and GAPDH (Glyceraldehyde 3-Phosphate dehydrogenase) expression, predicts the metabolic state of a cell [59]. A higher BEC is an indicator of active OXPHOS. In one study, thirty six of 55 HGSOC patients had a BEC of less than 2.65 [60]. Progression free survival was higher in patients with $<2.65$ compared to the 19 patients with higher 
BEC ( 9.8 versus 5.3 months). However, the BEC does not account for metabolic heterogeneity and therefore these observations do not rule out the presence of tumor foci with active OXPHOS. There is evidence that agents targeting OXPHOS can be used to target cancer initiating cells, chemoresistant tumors as well as non-tumor cells from the tumor microenvironment.

\subsection{Reliance of Ovarian Cancer Stem Cells on OXPHOS}

Perhaps the largest impact of OXPHOS is in the survival and proliferation of cancer initiating stem cells. Tumor initiating cells isolated from tumorigenic murine ovarian surface epithelial (MOSE) cells showed increased expression of glucose transporters and an overactive glycolytic pathway [61,62]. However, these tumor initiating cells also had a higher capacity than non-tumor initiating tumor-forming MOSE cells for mitochondrial oxygen consumption. The tumor initiating MOSE cells also exhibited higher survivability when cultured in media that did not contain glucose but was supplemented with glutamine and fatty acids. The observation that the tumor initiating cells are better able to survive on glutamine-supplemented media suggests that they are less dependent on glycolysis and, through the entry of glutamine in the tricarboxylic acid cycle are able to generate sufficient NADH (Nicotinamide Adenine Dinucleotide) and FADH2 (Flavine Adenine Dinucleotide). The higher mitochondrial capacity facilitates production of sufficient levels of ATP that drive their proliferation.

$\mathrm{CD} 44^{+} / \mathrm{CD} 117^{+}$cancer stem cells isolated from the peritoneal fluid of HGSOC patients that had the ability to form tumors in mice, showed decreased levels of pyruvate dehydrogenase kinase (PDHK1) and increased expression of isocitrate dehydrogenase (IDH2) [18]. This observation is in stark contrast to the non-cancer stem cells $\left(\mathrm{CD} 44^{+} / \mathrm{CD} 117^{-}\right)$from HGSOC patients where the PDHK1 was upregulated and IDH2 was significantly lower. PDHK1 negatively regulates pyruvate dehydrogenase and as a result controls the amount of acetyl-CoA (Coenzyme A) available for the tricarboxylic acid cycle. The decrease in PDHK1 and increase in IDH2 in the $\mathrm{CD} 44^{+} / \mathrm{CD} 117^{+}$ovarian cancer stem cell population are indicators of enhanced tricarboxylic acid cycle. The CD44 ${ }^{+} / \mathrm{CD} 117^{+}$cancer stem cells produced higher levels of oxygen radicals and had enhanced OXPHOS than the non-stem cell $\left(\mathrm{CD} 44^{+} / \mathrm{CD} 117^{-}\right)$population. RAG2 ${ }^{-/-}$mice implanted with HGSOC tumors when maintained on a diet supplemented with the glycolysis inhibitor, 2-deoxyglucose, instead of glucose, showed a decrease in tumor size. However, the surviving tumors from these mice were enriched in $\mathrm{CD} 44^{+} / \mathrm{CD} 117^{+}$cancer stem cells [18].

\subsection{OXPHOS in Chemoresistant HGSOC}

There is also evidence that OXPHOS is an important pathway to target in chemoresistant tumors. Tumor necrosis factor receptor-associated protein 1 (TRAP1) is a mitochondrial chaperone from the Hsp90 family [63]. Increase in TRAP1 expression elevates aerobic glycolysis in ovarian cancer cell lines [64]. HGSOC lines with lower expression of TRAP1 or silencing of this gene increased the oxygen consumption rate and decreased extracellular acidification (a measure of aerobic glycolysis) [65]. Low expression of TRAP1 results in higher reliance on OXPHOS and is associated with resistance to platinum [64]. Chemoresistant ovarian cancer cells show increased OXPHOS activity and survive under limiting glucose levels or when the resistant tumors were implanted in mice that were fed 2-deoxyglucose [34].

\subsection{OXPHOS and the Tumor Microenvironment}

Tumor cells produce high levels of lactic acid in the tumor microenvironment. While the lactic acid can be transported by cancer cells through monocarboxylic acid transporters (MCTs) and used to promote tumor proliferation, the effect of the acidic environment on the non-malignant cells is also an important factor to consider when determining the metabolic profile of the tumor. For example, the lactic acid in the tumor microenvironment can regulate the activity of immune cells infiltrating the tumor microenvironment (reviewed in [66]). 
Such crosstalk in the tumor microenvironment is not unidirectional as the tumor cells can also be affected by the metabolic status of the fibroblasts from the microenvironment. For example, Ras (glycine at position 12 mutated to valine) mutations alter metabolism in cancer cells and increase the release of oxygen radicals [67]. These radicals induce oxidative stress in the intratumoral stroma, forcing a catabolic state that produces lactate, ketones, glutamine and fatty acids that serve as fuel to the cancer.

Stromal cells from the tumor microenvironment express low levels of caveolin 1 and high MCT4 allowing them to expel lactate into the tumor microenvironment [68-70]. In a recent study, patients with BRCA1 mutated breast cancers were treated with the anti-oxidant, $N$-acetyl cysteine [71]. Pathological examination showed a reversal in the expression of caveolin 1 and MCT4 by the stromal cells suggesting that neutralization of the oxygen radicals can inhibit the symbiotic relationship between the cancer cells and the stromal cells in the microenvironment. Additionally, this study also observed a decrease in ki67 stained cancer cells. Since the mitochondria are the major source for oxygen radicals, it can be argued that the stromal cells from the tumor microenvironment are OXPHOS-active and the oxygen radicals generated by these cells promote the proliferation of cancer cells. Therefore, inhibitors of OXPHOS can not only be successful because of their direct cytotoxic effects on cancer cells but also through the potential modulation of metabolism in stromal and other non-cancer cells from the tumor microenvironment.

\section{OXPHOS Provides Multiple Targets for Drug Development}

High energy electrons from NADH and $\mathrm{FADH}_{2}$ are harvested in OXPHOS and transferred to molecular oxygen. Four multiprotein complexes located in the inner membrane of the mitochondria (Complexes I-IV) are required for electron transport (Figure 1). Electrons from NADH and FADH 2 are extracted in complex I and complex II, respectively. Electrons from complex I and II are delivered to complex III via the electron carrier, ubiquinone (coenzyme 10, CoQ10). The quinone head group of CoQ10 participates in two electron redox reactions. Addition of one electron to CoQ10 yields semiquinone and further reduction of this intermediate leads to formation of ubiquinol. The electron transfer from $\mathrm{NADH} / \mathrm{FADH}_{2}$ to ubiquinone occurs at the ubiquinone and ubiquinol binding sites, $\mathrm{Q}_{0}$ and $\mathrm{Q}_{\mathrm{i}}$, in the mitochondrial complexes I-III. Electron transport from complex III to complex IV is aided by cytochrome $\mathrm{C}(\mathrm{Cyt} C)$. In complex IV, the electrons are delivered to molecular oxygen to form water.

The transfer of electrons is coupled with pumping of protons from the matrix to the intermembrane of the mitochondria. This transfer of protons leads to the maintenance of a proton gradient $\left(\Delta \Psi_{\text {pion }}\right)$. The proton efflux from the matrix helps maintain a negative charge in the matrix and contributes to an electrical potential gradient $\left(\Delta \Psi_{\mathrm{m}}\right)$. The electromotive force generated through proton transport provides the energy necessary for the fifth mitochondrial complex, the ATP synthase, to convert ADP to ATP.

Complex chemical reactions and biochemical control points are required to regulate OXPHOS. From the standpoint of cancer drug discovery, this situation provides opportunities for the development of novel therapeutic strategies. Agents that interfere with electron transport, maintenance of the proton gradient $\left(\Delta \Psi_{\text {pion }}\right.$ and $\left.\Delta \Psi_{\mathrm{m}}\right)$ and transfer of electrons to oxygen and ATP synthesis can be developed as cancer therapeutics. While small molecules are likely the preferred agents to target OXPHOS, efforts are also underway to develop peptides that can specifically target this mitochondrial metabolic pathway (reviewed in Reference [72]). In the subsequent sections, we will discuss small molecule agents that interfere with OXPHOS. 


\section{OXPHOS Inhibitors}

\subsection{Complex I Inhibiting Biguanides}

Metformin and proguanil are biguanides with complex I inhibitory activities (Figure 1). Regular use of metformin reduces risk of ovarian cancer (OR 0.61, 95\% CI 0.3-1.25) [73]. Nearly 70\% of HGSOC patients using metformin survived for 5 years. In comparison, only $47 \%$ of HGSOC patients who were not on metformin survived for 5-years or more [74]. Romero and colleagues have analyzed the positive benefits of metformin use in HGSOC patients with diabetes. Approximately $51 \%$ of the diabetic patients who regularly used metformin had progression-free survival at 5 -years post initial diagnosis of the cancer. In contrast, $23 \%$ of the nondiabetic metformin users and only $8 \%$ of non-diabetic non-metformin users had progression free survival at 5 -years postdiagnosis [75]. The overall survival at 5 -years post initial diagnosis of HGSOC was reported to be $63 \%, 37 \%$ and $23 \%$, respectively, for these three cohorts [75].

Metformin inhibits complex I and thereby reduces ATP production. As a result of decreased ATP levels, AMPK is activated in cancer cells along with inhibition of mTORC1 (mammalian Target of Rapamycin Complex). Millimolar concentrations of metformin are required to inhibit complex I activity and there remains an active question of whether such high levels of metformin can be achieved in solid tumors. Proguanil inhibits complex I activity in the malarial parasite and is therefore administered in conjunction with atovaquone, a complex III inhibitor. However, proguanil has limited effect on human complex I and is therefore not suitable for cancer therapy [76,77]. Another bigiuanide, phenformin triggers lactic acidosis and therefore has major clinical toxicity.

A novel agent, IACS-0107059, that likely mimics the biguanide functional group has been investigated as therapy for acute myeloid leukemia [78-82]. This compound blocks complex I at subnanomolar-nanomolar range and inhibits proliferation of HGSOC cells. Clinical trials are currently underway to test this compound against AML and solid tumors.

Eight clinical trials are currently posted in clinicaltrials.gov to test the effect of metformin in ovarian cancer patients. The majority of these trials are evaluating the combination of metformin with chemotherapy and are currently recruiting patients. Results from one trial (NCT01579812) showed that metformin was well tolerated. Ex vivo evaluation of the tumors showed significant decrease in viable cancer stem cell population. Additional studies are needed to determine if these positive benefits are due to the OXPHOS inhibitory effects of metformin. As demonstrated by Yu et al. [58], monitoring pAMPK and HIF- $1 \alpha$ levels in the metformin clinical trials can potentially be used as biomarkers for the status of OXPHOS versus aerobic glycolysis in tumors providing insight into the metabolic adaptations occurring in the tumors in response to this biguanide.

\subsection{Oxidative Stress Inducers}

Oxidative stress results from an imbalance between the processes responsible for generation and sequestration of reactive oxygen radicals (ROS) [83]. Since the transfer of electrons to molecular oxygen is an integral step of the electron transport chain, the OXPHOS pathway is a major generator of oxygen radicals (Figure 2). A rapid increase in intracellular levels of oxygen radicals causes cellular damage and cell death. Atovaquone, a Food and Drug Administration (FDA) approved anti-malarial agent that inhibits complex III activity, is being repurposed for treatment of solid tumors [84-86]. 


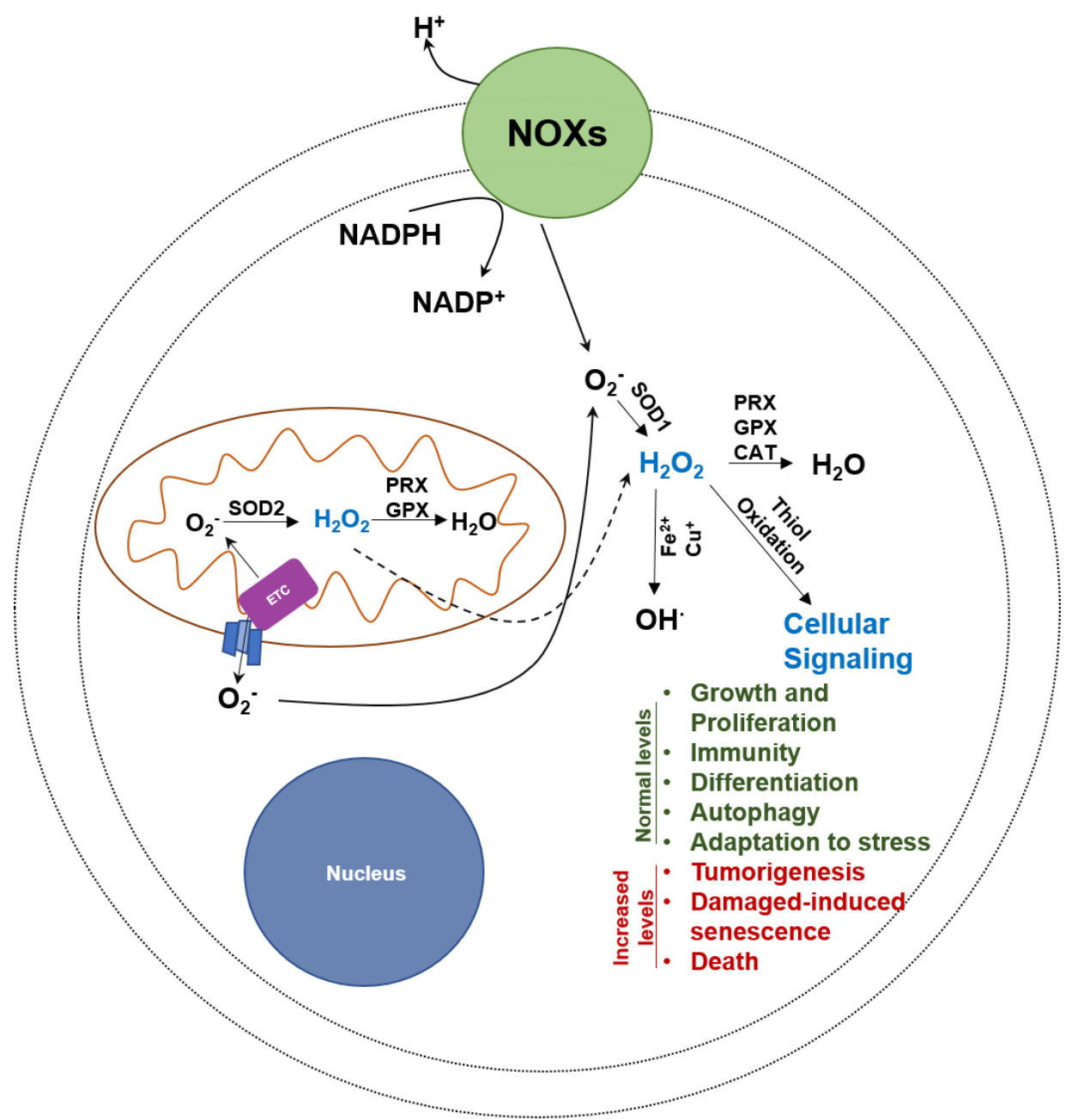

Figure 2. Uncontrolled oxidative stress is cytotoxic to cancer cells. OXPHOS is a major producer of oxygen radicals. While oxygen radicals have positive benefits in cells, a rapid and uncontrolled rise in hydroxyl radicals can lead to cancer cell death. PRX, peroxiredoxin, GPX, glutathione peroxidase, CAT, catalase, SOD, superoxide dismutase, and NOX, NADPH oxidase.

Unpublished results from our group are demonstrating that atovaquone should be investigated for treatment of HGSOC. The naphthoquinone unit of atovaquone engages in redox reactions and interferes with electron transport mediated by ubiquinone [84-86].

There are several naturally occurring and synthetic molecules that contain the quinone, naphthoquinone or anthroquinone head groups. Plumbagin and juglone are examples of such compounds. Treatment of HGSOC cells with plumbagin results in an immediate increase in intracellular oxygen radical flux [87]. Plumbagin also inhibits oxygen consumption rate, decreases ATP synthesis and increases the redox ratio (NADH/FAD) and extracellular acidification rate (ECAR) [87]. These results indicate that plumbagin is likely to be an inhibitor of mitochondrial electron transport.

Molecules that interfere with ubiquinone-mediated electron transport induce severe oxidative stress. There are at three major types of reactive oxygen species (superoxide anion $\mathrm{O}_{2}{ }^{-}$, hydrogen peroxide $\mathrm{H}_{2} \mathrm{O}_{2}$ and hydroxyl radicals $\mathrm{OH}^{-}$) that are formed due to incomplete transfer of electrons to molecular oxygen (Figure 2).

\subsection{Superoxide Anion $\left(\mathrm{O}_{2}{ }^{-}\right)$}

The primary source of superoxide anions is the electron transport chain in the mitochondria $[88,89]$. Leakage of electrons travelling through the multiple complexes in the electron transport chain results 
in one-electron reduction of oxygen to produce the superoxide anions. The second major producer of the superoxide anion are the NADPH oxidases (NOXs) which are transmembrane enzymes present at the different membranes in the cell (Figure 2) [90]. Superoxide anions are restricted in the cellular damage they can cause because they typically only react with peptide epitopes located near the iron sulfur complexes and hence do not cause indiscriminate cellular damage [91].

\subsection{Hydrogen Peroxide $\left(\mathrm{H}_{2} \mathrm{O}_{2}\right)$}

Reduction of the superoxide anions by superoxide dismutases (SODs) yields hydrogen peroxide $\left(\mathrm{H}_{2} \mathrm{O}_{2}\right) . \mathrm{H}_{2} \mathrm{O}_{2}$, existing at nanomolar concentration in the cell, is the main ROS signaling molecule of the cell. It functions by oxidizing the thiolate anion $\left(\mathrm{Cys}^{-} \mathrm{S}^{-}\right)$of a cysteine to its sulfenic form $\left(\mathrm{Cys}-\mathrm{SO}^{-}\right)$. Oxidation of the cysteine thiol affects the formation of Inter- and Intramolecular disulfide bonds and has serious consequences on the biological properties of proteins [92]. This oxidation is reversed by the enzymatic action of thioredoxin (TRX) and glutaredoxin (GRX), which themselves are reduced back by thioredoxin reductase (TR). These set of enzymes essentially constitute the main group of molecules executing the redox signaling in the cell [93]. At abnormally high concentrations of $\mathrm{H}_{2} \mathrm{O}_{2}$ (as those observed during oxidative stress), the sulfenic form (Cys-SO ${ }^{-}$) is irreversibly oxidized to higher oxidized states of sulfinic $\left(\mathrm{Cys}-\mathrm{SO}_{2}{ }^{-}\right)$and sulfonic $\left(\mathrm{Cys}-\mathrm{SO}_{3}{ }^{-}\right)$, which cannot be repaired through redox control and hence can cause significant cellular damage.

\subsection{Hydroxyl Radical (OH')}

The hydroxyl radical $\left(\mathrm{OH}^{-}\right)$is the most reactive of the three ROS molecules described in this section. $\mathrm{H}_{2} \mathrm{O}_{2}$ reacts with metal cations $\left(\mathrm{Fe}^{2+}, \mathrm{Cu}^{+}\right)$present in the cytosol in a reaction called Fenton reaction, to produce $\mathrm{OH}$. Additionally, nitric oxide synthases (NOS) also produce $\mathrm{OH}^{-}$along with $\mathrm{NO}_{2} \cdot$ under limiting concentration of cofactors and co-substrates. $\mathrm{OH}$ reacts indiscriminately with various substrates such as lipids, proteins and DNA and leads to genomic instability [94]. Presence of $\mathrm{OH}^{\prime}$ is abnormal and therefore, an indicator of high oxidative stress in the cell.

Oxidative stress induces pleiotropic effects in the cells. These include, but are not restricted to, activation of p53, inhibition of NFkB (Nuclear Factor kappa-B), activation of protein kinases and other signaling molecules, and decrease in the expression of survivin. Molecules such as plumbagin that increase intracellular oxygen radicals, are often thought to mediate pleiotropic effects that culminate in cancer cell death. However, it is important to consider that such molecules may also be specific in their ability to compete with ubiquinone and inhibit electron transport in the mitochondria and can therefore serve as important OXPHOS-targeting agents.

\section{Barriers to Using OXPHOS Inhibitors for HGSOC Therapy}

\subsection{Potential Toxicity of OXPHOS Inhibitors}

Our studies with plumbagin clearly show that inhibition of electron transport results in a rapid increase in harmful oxygen radicals that cause significant cellular damage [87]. With OXPHOS serving as a major mechanism for energy generation, there is significant risk that inhibitors of this pathway may damage healthy tissues. Toxicity of the OXPHOS inhibitors is therefore a major concern that may curtail their use for the treatment of HGSOC and other tumors. It should be noted, however, that plumbagin did not produce major toxicity in pre-clinical studies in mouse models [95,96]. Additionally, metformin is generally a safe drug with minimum toxicity. While proguanil is effective inhibitor of the OXPHOS pathway in the malarial and other parasites, its specific activity as OXPHOS inhibitor is reduced in human cells [76,77]. This experience with atovaquone and proguanil suggests that rational drug development approaches can be applied to develop inhibitors that have higher potency against human OXPHOS complexes. Given the higher susceptibility of cancer cells to oxidative stress, well-designed and more potent inhibitors can potentially be used at lower concentrations to produce optimum activity in tumors while reducing toxicity in healthy tissues. Additionally, the OXPHOS 
inhibitors can also be functionalized with folate and other tumor targeting moieties to facilitate selective delivery of these agents to the tumor, thereby achieving higher efficacy with lower toxicity.

\subsection{Anti-Oxidant Mechanisms and Chemoresistance}

There are elaborate antioxidant mechanisms to maintain steady state levels of oxygen radicals in all cells. Superoxide dismutase, catalase, peroxiredoxins, glutathione, glutathione reductase, thioredoxins and others form the network of anti-oxidant mechanisms that control oxidative stress. This network is controlled by a master regulatory transcription factor, Nrf-2. Cancer cells respond to inhibition of complex III by atovaquone, (unpublished observation) and plumbagin [87] by increasing the expression of Nrf-2. Therefore, the oxidative stress triggered by these agents is relatively short lived and therefore attenuates their cytolytic activity. The rise in Nrf-2 should therefore be considered as a chemoresistance mechanism to oxidative stress-inducing OXPHOS inhibitors. Combining these OXPHOS inhibitors with Nrf-2 modulators such as brusatol, results in a synergistic increase in inhibition of cancer cell proliferation [87]. Agents that enhance Nrf-2 activity are being developed to control oxidative damage in neurologic diseases. Similar efforts are needed to develop Nrf-2 inhibitors to enhance oxidative stress in HGSOC and other tumors.

Use of Nrf-2 inhibitors for cancer treatment also raises the possibility that such approaches may inhibit the natural protection against oxygen radicals in healthy tissues. Rational drug design, targeted delivery and specific drug formulations will be required to maximize the effect of Nrf- 2 inhibitors in cancer cells while attenuating the side-effects of such drugs in healthy tissues.

\subsection{Mitochondrial Adaptations to Oxidative Stress}

The extensive use of atovaquone has led to the realization that some malarial parasites have developed resistance to this drug through mutations in cytochrome B (Cyt B), an essential component of complex III [97-100]. Cyt B is encoded by the mitochondrial genome. The mitochondrial population with mutated Cyt $B$ is likely to be exposed to minimum oxidative damage in response to atovaquone and will therefore show enrichment through successive mitochondrial replications. A similar situation can also be envisioned in cancer where oxidative stress-inducing OXPHOS inhibitors may result in an increase in the drug-resistant mitochondrial pool. Studies are needed to determine the contributions of such mitochondrial adaptations to chemoresistance against OXPHOS inhibitors.

\section{Conclusions}

Inhibition of glucose metabolism will result in significantly curtailing the ability of cancer cells to proliferate and modulate the tumor microenvironment through the release of lactic acid and other intermediates. OXPHOS pathway in tumors, cancer stem cells and the stromal and immune cells in the tumor microenvironment is recognized as a target for development of novel anti-cancer therapies. The multimeric complexes of the OXPHOS pathway are targets for small molecule inhibitors that can inhibit metabolism as well as induce oxidative damage and cancer cell death. OXPHOS inhibitors can be paired with immunologic and other therapies. While the development of novel OXPHOS inhibitors will be necessary, it will be important that these agents are specifically targeted to the cancer or the tumor microenvironment in order to reduce toxicity in healthy tissues. Finally, the use of OXPHOS inhibitors may result in Nrf-2 activation and mitochondrial adaptations that may pose as pathways that are typically not considered to contribute towards chemoresistance. Studies on atovaquone, proguanil, metformin have provided the foundation that will support the development of additional and more potent OXPHOS inhibitors for the treatment of HGSOC and other tumors.

Author Contributions: This manuscript was conceptualized by A.P.N. and M.S.P. who also compiled the majority of the text. A.P.N. and A.K. collected the data necessary to interpret the literature and propose the central concept of this review. L.B. participated in discussions and helped write the text and provided her clinical expertise.

Funding: This research was funded by the Department of Obstetrics and Gynecology and funds from the Wisconsin Ovarian Cancer Alliance (WOCA) to M.S.P. and L.B. 
Acknowledgments: Support from the University of Wisconsin Carbone Cancer Center Support Grant P30 CA014520 that supports the Flow Lab and the Small Molecule Screening Facility is acknowledged.

Conflicts of Interest: Authors declare no conflict of interest.

\section{References}

1. Warburg, O.; Wind, F.; Negelein, E. The metabolism of tumors in the body. J. Gen. Physiol. 1927, 8, 519-530. [CrossRef] [PubMed]

2. Cori, C.F.; Cori, G.T. The Carbohydrate metabolism of tumors: I. The free sugar, lactic acid, and glycogen content of malignant tumors. J. Biol. Chem. 1925, 64, 11-22.

3. Warburg, O. On the origin of cancer cells. Science 1956, 123, 309-314. [CrossRef] [PubMed]

4. Warburg, O. On respiratory impairment in cancer cells. Science 1956, 124, 269-270. [PubMed]

5. Hatzivassiliou, G.; Zhao, F.; Bauer, D.E.; Andreadis, C.; Shaw, A.N.; Dhanak, D.; Hingorani, S.R.; Tuveson, D.A.; Thompson, C.B. ATP citrate lyase inhibition can suppress tumor cell growth. Cancer Cell 2005, 8, 311-321. [CrossRef] [PubMed]

6. Menendez, J.A.; Lupu, R. Fatty acid synthase and the lipogenic phenotype in cancer pathogenesis. Nat. Rev. Cancer 2007, 7, 763-777. [CrossRef] [PubMed]

7. Christofk, H.R.; Vander Heiden, M.G.; Harris, M.H.; Ramanathan, A.; Gerszten, R.E.; Wei, R.; Fleming, M.D.; Schreiber, S.L.; Cantley, L.C. The M2 splice isoform of pyruvate kinase is important for cancer metabolism and tumour growth. Nature 2008, 452, 230-233. [CrossRef] [PubMed]

8. Christofk, H.R.; Vander Heiden, M.G.; Wu, N.; Asara, J.M.; Cantley, L.C. Pyruvate kinase M2 is a phosphotyrosine-binding protein. Nature 2008, 452, 181-186. [CrossRef] [PubMed]

9. Boxer, M.B.; Jiang, J.K.; Vander Heiden, M.G.; Shen, M.; Skoumbourdis, A.P.; Southall, N.; Veith, H.; Leister, W.; Austin, C.P.; Park, H.W.; et al. Evaluation of substituted N,N'diarylsulfonamides as activators of the tumor cell specific M2 isoform of pyruvate kinase. J. Med. Chem. 2010, 53, 1048-1055. [CrossRef] [PubMed]

10. Anastasiou, D.; Yu, Y.; Israelsen, W.J.; Jiang, J.K.; Boxer, M.B.; Hong, B.S.; Tempel, W.; Dimov, S.; Shen, M.; Jha, A.; et al. Pyruvate kinase M2 activators promote tetramer formation and suppress tumorigenesis. Nat. Chem. Biol. 2012, 8, 839-847. [CrossRef] [PubMed]

11. Ning, X.; Qi, H.; Li, R.; Jin, Y.; McNutt, M.A.; Yin, Y. Synthesis and antitumor activity of novel 2, 3-didithiocarbamate substituted naphthoquinones as inhibitors of pyruvate kinase M2 isoform. J. Enzyme Inhib. Med. Chem. 2018, 33, 126-129. [CrossRef] [PubMed]

12. Sugden, M.C.; Holness, M.J. Therapeutic potential of the mammalian pyruvate dehydrogenase kinases in the prevention of hyperglycaemia. Curr. Drug Targets Immune Endocr. Metabol. Disord. 2002, 2, 151-165. [CrossRef] [PubMed]

13. Zhang, W.; Zhang, S.L.; Hu, X.; Tam, K.Y. Phenyl butyrate inhibits pyruvate dehydrogenase kinase 1 and contributes to its anti-cancer effect. Eur. J. Pharm. Sci. 2017, 110, 93-100. [CrossRef] [PubMed]

14. Zhang, S.L.; Hu, X.; Zhang, W.; Yao, H.; Tam, K.Y. Development of pyruvate dehydrogenase kinase inhibitors in medicinal chemistry with particular emphasis as anticancer agents. Drug Discov. Today 2015, 20, 1112-1119. [CrossRef] [PubMed]

15. Abdel-Magid, A.F. Inhibitors of Mutant IDH for the Treatment of Cancer. ACS Med. Chem. Lett. 2014, 5, 1184-1185. [CrossRef] [PubMed]

16. Wang, H.; Huwaimel, B.; Verma, K.; Miller, J.; Germain, T.M.; Kinarivala, N.; Pappas, D.; Brookes, P.S.; Trippier, P.C. Synthesis and Antineoplastic Evaluation of Mitochondrial Complex II (Succinate Dehydrogenase) Inhibitors Derived from Atpenin A5. ChemMedChem 2017, 12, 1033-1044. [CrossRef] [PubMed]

17. Rai, G.; Brimacombe, K.R.; Mott, B.T.; Urban, D.J.; Hu, X.; Yang, S.M.; Lee, T.D.; Cheff, D.M.; Kouznetsova, J.; Benavides, G.A.; et al. Discovery and Optimization of Potent, Cell-Active Pyrazole-Based Inhibitors of Lactate Dehydrogenase (LDH). J. Med. Chem. 2017, 60, 9184-9204. [CrossRef] [PubMed]

18. Pasto, A.; Bellio, C.; Pilotto, G.; Ciminale, V.; Silic-Benussi, M.; Guzzo, G.; Rasola, A.; Frasson, C.; Nardo, G.; Zulato, E.; et al. Cancer stem cells from epithelial ovarian cancer patients privilege oxidative phosphorylation, and resist glucose deprivation. Oncotarget 2014, 5, 4305-4319. [CrossRef] [PubMed] 
19. De Luca, A.; Fiorillo, M.; Peiris-Pages, M.; Ozsvari, B.; Smith, D.L.; Sanchez-Alvarez, R.; Martinez-Outschoorn, U.E.; Cappello, A.R.; Pezzi, V.; Lisanti, M.P.; et al. Mitochondrial biogenesis is required for the anchorage-independent survival and propagation of stem-like cancer cells. Oncotarget 2015, 6, 14777-14795. [CrossRef] [PubMed]

20. Lamb, R.; Bonuccelli, G.; Ozsvari, B.; Peiris-Pages, M.; Fiorillo, M.; Smith, D.L.; Bevilacqua, G.; Mazzanti, C.M.; McDonnell, L.A.; Naccarato, A.G.; et al. Mitochondrial mass, a new metabolic biomarker for stem-like cancer cells: Understanding WNT/FGF-driven anabolic signaling. Oncotarget 2015, 6, 30453-30471. [CrossRef] [PubMed]

21. Kurman, R.J.; Shih Ie, M. Molecular pathogenesis and extraovarian origin of epithelial ovarian cancer-shifting the paradigm. Hum. Pathol. 2011, 42, 918-931. [CrossRef] [PubMed]

22. Kurman, R.J.; Shih Ie, M. The origin and pathogenesis of epithelial ovarian cancer: A proposed unifying theory. Am. J. Surg. Pathol. 2010, 34, 433-443. [CrossRef] [PubMed]

23. Kurman, R.J.; Shih Ie, M. Pathogenesis of ovarian cancer: lessons from morphology and molecular biology and their clinical implications. Int. J. Gynecol. Pathol. 2008, 27, 151-160. [CrossRef] [PubMed]

24. Network, C.G.A.R. Integrated genomic analyses of ovarian carcinoma. Nature 2011, 474, 609-615. [CrossRef]

25. Kuhn, E.; Kurman, R.J.; Vang, R.; Sehdev, A.S.; Han, G.; Soslow, R.; Wang, T.L.; Shih Ie, M. TP53 mutations in serous tubal intraepithelial carcinoma and concurrent pelvic high-grade serous carcinoma-evidence supporting the clonal relationship of the two lesions. J. Pathol. 2012, 226, 421-426. [CrossRef] [PubMed]

26. Vang, R.; Levine, D.A.; Soslow, R.A.; Zaloudek, C.; Shih Ie, M.; Kurman, R.J. Molecular Alterations of TP53 are a Defining Feature of Ovarian High-Grade Serous Carcinoma: A Rereview of Cases Lacking TP53 Mutations in The Cancer Genome Atlas Ovarian Study. Int. J. Gynecol. Pathol. 2016, 35, 48-55. [CrossRef] [PubMed]

27. Kindelberger, D.W.; Lee, Y.; Miron, A.; Hirsch, M.S.; Feltmate, C.; Medeiros, F.; Callahan, M.J.; Garner, E.O.; Gordon, R.W.; Birch, C.; et al. Intraepithelial carcinoma of the fimbria and pelvic serous carcinoma: Evidence for a causal relationship. Am. J. Surg. Pathol. 2007, 31, 161-169. [CrossRef] [PubMed]

28. Perets, R.; Wyant, G.A.; Muto, K.W.; Bijron, J.G.; Poole, B.B.; Chin, K.T.; Chen, J.Y.; Ohman, A.W.; Stepule, C.D.; Kwak, S.; et al. Transformation of the fallopian tube secretory epithelium leads to high-grade serous ovarian cancer in Brca;Tp53;Pten models. Cancer Cell 2013, 24, 751-765. [CrossRef] [PubMed]

29. Przybycin, C.G.; Kurman, R.J.; Ronnett, B.M.; Shih Ie, M.; Vang, R. Are all pelvic (nonuterine) serous carcinomas of tubal origin? Am. J. Surg. Pathol. 2010, 34, 1407-1416. [CrossRef] [PubMed]

30. Matulonis, U.A.; Harter, P.; Gourley, C.; Friedlander, M.; Vergote, I.; Rustin, G.; Scott, C.; Meier, W.; Shapira-Frommer, R.; Safra, T.; et al. Olaparib maintenance therapy in patients with platinum-sensitive, relapsed serous ovarian cancer and a BRCA mutation: Overall survival adjusted for postprogression poly(adenosine diphosphate ribose) polymerase inhibitor therapy. Cancer 2016, 122, 1844-1852. [CrossRef] [PubMed]

31. Ledermann, J.A.; Harter, P.; Gourley, C.; Friedlander, M.; Vergote, I.; Rustin, G.; Scott, C.; Meier, W.; Shapira-Frommer, R.; Safra, T.; et al. Overall survival in patients with platinum-sensitive recurrent serous ovarian cancer receiving olaparib maintenance monotherapy: An updated analysis from a randomised, placebo-controlled, double-blind, phase 2 trial. Lancet Oncol. 2016, 17, 1579-1589. [CrossRef]

32. Ledermann, J.; Harter, P.; Gourley, C.; Friedlander, M.; Vergote, I.; Rustin, G.; Scott, C.L.; Meier, W.; Shapira-Frommer, R.; Safra, T.; et al. Olaparib maintenance therapy in patients with platinum-sensitive relapsed serous ovarian cancer: A preplanned retrospective analysis of outcomes by BRCA status in a randomised phase 2 trial. Lancet Oncol. 2014, 15, 852-861. [CrossRef]

33. Ledermann, J.; Harter, P.; Gourley, C.; Friedlander, M.; Vergote, I.; Rustin, G.; Scott, C.; Meier, W.; Shapira-Frommer, R.; Safra, T.; et al. Olaparib maintenance therapy in platinum-sensitive relapsed ovarian cancer. N. Engl. J. Med. 2012, 366, 1382-1392. [CrossRef] [PubMed]

34. Dar, S.; Chhina, J.; Mert, I.; Chitale, D.; Buekers, T.; Kaur, H.; Giri, S.; Munkarah, A.; Rattan, R. Bioenergetic Adaptations in Chemoresistant Ovarian Cancer Cells. Sci. Rep. 2017, 7, 8760. [CrossRef] [PubMed]

35. Anderson, A.S.; Roberts, P.C.; Frisard, M.I.; McMillan, R.P.; Brown, T.J.; Lawless, M.H.; Hulver, M.W.; Schmelz, E.M. Metabolic changes during ovarian cancer progression as targets for sphingosine treatment. Exp. Cell Res. 2013, 319, 1431-1442. [CrossRef] [PubMed] 
36. Dier, U.; Shin, D.H.; Hemachandra, L.P.; Uusitalo, L.M.; Hempel, N. Bioenergetic analysis of ovarian cancer cell lines: Profiling of histological subtypes and identification of a mitochondria-defective cell line. PLOS ONE 2014, 9, e98479. [CrossRef] [PubMed]

37. Chao, T.K.; Huang, T.S.; Liao, Y.P.; Huang, R.L.; Su, P.H.; Shen, H.Y.; Lai, H.C.; Wang, Y.C. Pyruvate kinase M2 is a poor prognostic marker of and a therapeutic target in ovarian cancer. PLoS ONE 2017, 12, e0182166. [CrossRef] [PubMed]

38. Jin, Z.; Gu, J.; Xin, X.; Li, Y.; Wang, H. Expression of hexokinase 2 in epithelial ovarian tumors and its clinical significance in serous ovarian cancer. Eur. J. Gynaecol. Oncol. 2014, 35, 519-524. [PubMed]

39. Xintaropoulou, C.; Ward, C.; Wise, A.; Queckborner, S.; Turnbull, A.; Michie, C.O.; Williams, A.R.W.; Rye, T.; Gourley, C.; Langdon, S.P. Expression of glycolytic enzymes in ovarian cancers and evaluation of the glycolytic pathway as a strategy for ovarian cancer treatment. BMC Cancer 2018, 18, 636. [CrossRef] [PubMed]

40. Suh, D.H.; Kim, M.A.; Kim, H.; Kim, M.K.; Kim, H.S.; Chung, H.H.; Kim, Y.B.; Song, Y.S. Association of overexpression of hexokinase II with chemoresistance in epithelial ovarian cancer. Clin. Exp. Med. 2014, 14, 345-353. [CrossRef] [PubMed]

41. Tsukioka, M.; Matsumoto, Y.; Noriyuki, M.; Yoshida, C.; Nobeyama, H.; Yoshida, H.; Yasui, T.; Sumi, T.; Honda, K.; Ishiko, O. Expression of glucose transporters in epithelial ovarian carcinoma: Correlation with clinical characteristics and tumor angiogenesis. Oncol. Rep. 2007, 18, 361-367. [CrossRef] [PubMed]

42. Kalir, T.; Wang, B.Y.; Goldfischer, M.; Haber, R.S.; Reder, I.; Demopoulos, R.; Cohen, C.J.; Burstein, D.E. Immunohistochemical staining of GLUT1 in benign, borderline, and malignant ovarian epithelia. Cancer 2002, 94, 1078-1082. [CrossRef] [PubMed]

43. Cho, H.; Lee, Y.S.; Kim, J.; Chung, J.Y.; Kim, J.H. Overexpression of glucose transporter-1 (GLUT-1) predicts poor prognosis in epithelial ovarian cancer. Cancer Investig. 2013, 31, 607-615. [CrossRef] [PubMed]

44. Kurokawa, T.; Yoshida, Y.; Kawahara, K.; Tsuchida, T.; Okazawa, H.; Fujibayashi, Y.; Yonekura, Y.; Kotsuji, F. Expression of GLUT-1 glucose transfer, cellular proliferation activity and grade of tumor correlate with [F-18]-fluorodeoxyglucose uptake by positron emission tomography in epithelial tumors of the ovary. Int. J. Cancer 2004, 109, 926-932. [CrossRef] [PubMed]

45. Hitosugi, T.; Kang, S.; Vander Heiden, M.G.; Chung, T.-W.; Elf, S.; Lythgoe, K.; Dong, S.; Lonial, S.; Wang, X.; Chen, G.Z.; et al. Tyrosine Phosphorylation Inhibits PKM2 to Promote the Warburg Effect and Tumor Growth. Sci. Signal. 2009, 2, ra73. [CrossRef] [PubMed]

46. Privat, M.; Radosevic-Robin, N.; Aubel, C.; Cayre, A.; Penault-Llorca, F.; Marceau, G.; Sapin, V.; Bignon, Y.J.; Morvan, D. BRCA1 induces major energetic metabolism reprogramming in breast cancer cells. PLoS ONE 2014, 9, e102438. [CrossRef] [PubMed]

47. Simabuco, F.M.; Morale, M.G.; Pavan, I.C.B.; Morelli, A.P.; Silva, F.R.; Tamura, R.E. p53 and metabolism: From mechanism to therapeutics. Oncotarget 2018, 9, 23780-23823. [CrossRef] [PubMed]

48. Lai, J.; Chien, J.; Staub, J.; Avula, R.; Greene, E.L.; Matthews, T.A.; Smith, D.I.; Kaufmann, S.H.; Roberts, L.R.; Shridhar, V. Loss of HSulf-1 up-regulates heparin-binding growth factor signaling in cancer. J. Biol. Chem. 2003, 278, 23107-23117. [CrossRef] [PubMed]

49. Mondal, S.; Roy, D.; Camacho-Pereira, J.; Khurana, A.; Chini, E.; Yang, L.; Baddour, J.; Stilles, K.; Padmabandu, S.; Leung, S.; et al. HSulf-1 deficiency dictates a metabolic reprograming of glycolysis and TCA cycle in ovarian cancer. Oncotarget 2015, 6, 33705-33719. [CrossRef] [PubMed]

50. Hayashi, J.; Takemitsu, M.; Nonaka, I. Recovery of the missing tumorigenicity in mitochondrial DNA-less HeLa cells by introduction of mitochondrial DNA from normal human cells. Somat. Cell Mol. Genet. 1992, 18, 123-129. [CrossRef] [PubMed]

51. Cavalli, L.R.; Varella-Garcia, M.; Liang, B.C. Diminished tumorigenic phenotype after depletion of mitochondrial DNA. Cell Growth Differ. 1997, 8, 1189-1198. [PubMed]

52. Morais, R.; Zinkewich-Peotti, K.; Parent, M.; Wang, H.; Babai, F.; Zollinger, M. Tumor-forming ability in athymic nude mice of human cell lines devoid of mitochondrial DNA. Cancer Res. 1994, 54, 3889-3896. [PubMed]

53. Lim, H.Y.; Ho, Q.S.; Low, J.; Choolani, M.; Wong, K.P. Respiratory competent mitochondria in human ovarian and peritoneal cancer. Mitochondrion 2011, 11, 437-443. [CrossRef] [PubMed] 
54. Tan, A.S.; Baty, J.W.; Dong, L.F.; Bezawork-Geleta, A.; Endaya, B.; Goodwin, J.; Bajzikova, M.; Kovarova, J.; Peterka, M.; Yan, B.; et al. Mitochondrial genome acquisition restores respiratory function and tumorigenic potential of cancer cells without mitochondrial DNA. Cell Metab. 2015, 21, 81-94. [CrossRef] [PubMed]

55. Viale, A.; Pettazzoni, P.; Lyssiotis, C.A.; Ying, H.; Sanchez, N.; Marchesini, M.; Carugo, A.; Green, T.; Seth, S.; Giuliani, V.; et al. Oncogene ablation-resistant pancreatic cancer cells depend on mitochondrial function. Nature 2014, 514, 628-632. [CrossRef] [PubMed]

56. Viale, A.; Corti, D.; Draetta, G.F. Tumors and mitochondrial respiration: A neglected connection. Cancer Res. 2015, 75, 3685-3686. [CrossRef] [PubMed]

57. Ying, H.; Kimmelman, A.C.; Lyssiotis, C.A.; Hua, S.; Chu, G.C.; Fletcher-Sananikone, E.; Locasale, J.W.; Son, J.; Zhang, H.; Coloff, J.L.; et al. Oncogenic Kras maintains pancreatic tumors through regulation of anabolic glucose metabolism. Cell 2012, 149, 656-670. [CrossRef] [PubMed]

58. Yu, L.; Lu, M.; Jia, D.; Ma, J.; Ben-Jacob, E.; Levine, H.; Kaipparettu, B.A.; Onuchic, J.N. Modeling the Genetic Regulation of Cancer Metabolism: Interplay between Glycolysis and Oxidative Phosphorylation. Cancer Res. 2017, 77, 1564-1574. [CrossRef] [PubMed]

59. Cuezva, J.M.; Krajewska, M.; de Heredia, M.L.; Krajewski, S.; Santamaria, G.; Kim, H.; Zapata, J.M.; Marusawa, H.; Chamorro, M.; Reed, J.C. The bioenergetic signature of cancer: A marker of tumor progression. Cancer Res. 2002, 62, 6674-6681. [PubMed]

60. Hjerpe, E.; Egyhazi Brage, S.; Carlson, J.; Frostvik Stolt, M.; Schedvins, K.; Johansson, H.; Shoshan, M.; Avall-Lundqvist, E. Metabolic markers GAPDH, PKM2, ATP5B and BEC-index in advanced serous ovarian cancer. BMC Clin. Pathol. 2013, 13, 30. [CrossRef] [PubMed]

61. Anderson, A.S.; Roberts, P.C.; Frisard, M.I.; Hulver, M.W.; Schmelz, E.M. Ovarian tumor-initiating cells display a flexible metabolism. Exp. Cell Res. 2014, 328, 44-57. [CrossRef] [PubMed]

62. Roberts, P.C.; Mottillo, E.P.; Baxa, A.C.; Heng, H.H.; Doyon-Reale, N.; Gregoire, L.; Lancaster, W.D.; Rabah, R.; Schmelz, E.M. Sequential molecular and cellular events during neoplastic progression: A mouse syngeneic ovarian cancer model. Neoplasia 2005, 7, 944-956. [CrossRef] [PubMed]

63. Song, H.Y.; Dunbar, J.D.; Zhang, Y.X.; Guo, D.; Donner, D.B. Identification of a protein with homology to hsp90 that binds the type 1 tumor necrosis factor receptor. J. Biol. Chem. 1995, 270, 3574-3581. [CrossRef] [PubMed]

64. Matassa, D.S.; Amoroso, M.R.; Lu, H.; Avolio, R.; Arzeni, D.; Procaccini, C.; Faicchia, D.; Maddalena, F.; Simeon, V.; Agliarulo, I.; et al. Oxidative metabolism drives inflammation-induced platinum resistance in human ovarian cancer. Cell Death Differ. 2016, 23, 1542-1554. [CrossRef] [PubMed]

65. Matassa, D.S.; Agliarulo, I.; Avolio, R.; Landriscina, M.; Esposito, F. TRAP1 regulation of cancer metabolism: Dual role as oncogene or tumor suppressor. Genes 2018, 9, 195. [CrossRef] [PubMed]

66. Morrot, A.; da Fonseca, L.M.; Salustiano, E.J.; Gentile, L.B.; Conde, L.; Filardy, A.A.; Franklim, T.N.; da Costa, K.M.; Freire-de-Lima, C.G.; Freire-de-Lima, L. Metabolic Symbiosis and Immunomodulation: How Tumor Cell-Derived Lactate May Disturb Innate and Adaptive Immune Responses. Front. Oncol. 2018, 8, 81. [CrossRef] [PubMed]

67. Martinez-Outschoorn, U.E.; Curry, J.M.; Ko, Y.H.; Lin, Z.; Tuluc, M.; Cognetti, D.; Birbe, R.C.; Pribitkin, E.; Bombonati, A.; Pestell, R.G.; et al. Oncogenes and inflammation rewire host energy metabolism in the tumor microenvironment: RAS and NFkappaB target stromal MCT4. Cell Cycle 2013, 12, 2580-2597. [CrossRef] [PubMed]

68. Whitaker-Menezes, D.; Martinez-Outschoorn, U.E.; Lin, Z.; Ertel, A.; Flomenberg, N.; Witkiewicz, A.K.; Birbe, R.C.; Howell, A.; Pavlides, S.; Gandara, R.; et al. Evidence for a stromal-epithelial "lactate shuttle" in human tumors: MCT4 is a marker of oxidative stress in cancer-associated fibroblasts. Cell Cycle 2011, 10, 1772-1783. [CrossRef] [PubMed]

69. Witkiewicz, A.K.; Dasgupta, A.; Nguyen, K.H.; Liu, C.; Kovatich, A.J.; Schwartz, G.F.; Pestell, R.G.; Sotgia, F.; Rui, H.; Lisanti, M.P. Stromal caveolin-1 levels predict early DCIS progression to invasive breast cancer. Cancer Biol. Ther. 2009, 8, 1071-1079. [CrossRef] [PubMed]

70. Sotgia, F.; Martinez-Outschoorn, U.E.; Lisanti, M.P. Cancer metabolism: New validated targets for drug discovery. Oncotarget 2013, 4, 1309-1316. [CrossRef] [PubMed] 
71. Monti, D.; Sotgia, F.; Whitaker-Menezes, D.; Tuluc, M.; Birbe, R.; Berger, A.; Lazar, M.; Cotzia, P.; Draganova-Tacheva, R.; Lin, Z.; et al. Pilot study demonstrating metabolic and anti-proliferative effects of in vivo anti-oxidant supplementation with N-Acetylcysteine in Breast Cancer. Semin. Oncol. 2017, 44, 226-232. [CrossRef] [PubMed]

72. Constance, J.E.; Lim, C.S. Targeting malignant mitochondria with therapeutic peptides. Ther. Deliv. 2012, 3, 961-979. [CrossRef] [PubMed]

73. Bodmer, M.; Becker, C.; Meier, C.; Jick, S.S.; Meier, C.R. Use of metformin and the risk of ovarian cancer: A case-control analysis. Gynecol. Oncol. 2011, 123, 200-204. [CrossRef] [PubMed]

74. Kumar, S.; Meuter, A.; Thapa, P.; Langstraat, C.; Giri, S.; Chien, J.; Rattan, R.; Cliby, W.; Shridhar, V. Metformin intake is associated with better survival in ovarian cancer: A case-control study. Cancer 2013, 119, 555-562. [CrossRef] [PubMed]

75. Romero, I.L.; McCormick, A.; McEwen, K.A.; Park, S.; Karrison, T.; Yamada, S.D.; Pannain, S.; Lengyel, E. Relationship of type II diabetes and metformin use to ovarian cancer progression, survival, and chemosensitivity. Obstet. Gynecol. 2012, 119, 61-67. [CrossRef] [PubMed]

76. Bakhru, A.; Buckanovich, R.J.; Griggs, J.J. The impact of diabetes on survival in women with ovarian cancer. Gynecol. Oncol. 2011, 121, 106-111. [CrossRef] [PubMed]

77. Bridges, H.R.; Sirvio, V.A.; Agip, A.N.; Hirst, J. Molecular features of biguanides required for targeting of mitochondrial respiratory complex I and activation of AMP-kinase. BMC Biol. 2016, 14, 65. [CrossRef] [PubMed]

78. Bridges, H.R.; Jones, A.J.; Pollak, M.N.; Hirst, J. Effects of metformin and other biguanides on oxidative phosphorylation in mitochondria. Biochem. J. 2014, 462, 475-487. [CrossRef] [PubMed]

79. Baran, N.; Han, L.; Herbrich, S.; Sweeney, S.R.; Lodi, A.; Gay, J.; Feng, N.; Molina, J.R.; Kaminski, M.; Guzman, M.L.; et al. Novel Complex I inhibitor IACS-010759 Targets Leukemia Initiating Cells (LICs) in AML Patients. Clin. Lymphoma Myeloma Leuk. 2017, 17, S297. [CrossRef]

80. Baran, N.; Molina, J.; Cavazos, A.; Harutyunyan, K.; Feng, N.; Gay, J.; Piya, S.; Shanmuga Velandy, S.; Jabbour, E.J.; Andreeff, M.; et al. Mitochondrial Complex I Inhibition with Iacs-010759 in T-ALL Preclinical Models. Blood 2016, 128, 4028.

81. Lissanu Deribe, Y.; Sun, Y.; Terranova, C.; Khan, F.; Martinez-Ledesma, J.; Gay, J.; Gao, G.; Mullinax, R.A.; Khor, T.; Feng, N.; et al. Mutations in the SWI/SNF complex induce a targetable dependence on oxidative phosphorylation in lung cancer. Nat. Med. 2018, 24, 1047-1057. [CrossRef] [PubMed]

82. Molina, J.R.; Sun, Y.; Protopopova, M.; Gera, S.; Bandi, M.; Bristow, C.; McAfoos, T.; Morlacchi, P.; Ackroyd, J.; Agip, A.A.; et al. An inhibitor of oxidative phosphorylation exploits cancer vulnerability. Nat. Med. 2018, 24, 1036-1046. [CrossRef] [PubMed]

83. Vangapandu, H.V.; Alston, B.; Morse, J.; Ayres, M.L.; Wierda, W.G.; Keating, M.J.; Marszalek, J.R.; Gandhi, V. Biological and metabolic effects of IACS-010759, an OxPhos inhibitor, on chronic lymphocytic leukemia cells. Oncotarget 2018, 9, 24980-24991. [CrossRef] [PubMed]

84. Sies, H. Oxidative Stress: Introductory Remarks; Academic Press: London, UK, 1985.

85. Lv, Z.; Yan, X.; Lu, L.; Su, C.; He, Y. Atovaquone enhances doxorubicin's efficacy via inhibiting mitochondrial respiration and STAT3 in aggressive thyroid cancer. J. Bioenerg. Biomembr. 2018, 50, 263-270. [CrossRef] [PubMed]

86. Fiorillo, M.; Lamb, R.; Tanowitz, H.B.; Mutti, L.; Krstic-Demonacos, M.; Cappello, A.R.; Martinez-Outschoorn, U.E.; Sotgia, F.; Lisanti, M.P. Repurposing atovaquone: Targeting mitochondrial complex III and OXPHOS to eradicate cancer stem cells. Oncotarget 2016, 7, 34084-34099. [CrossRef] [PubMed]

87. Ashton, T.M.; Fokas, E.; Kunz-Schughart, L.A.; Folkes, L.K.; Anbalagan, S.; Huether, M.; Kelly, C.J.; Pirovano, G.; Buffa, F.M.; Hammond, E.M.; et al. The anti-malarial atovaquone increases radiosensitivity by alleviating tumour hypoxia. Nat. Commun. 2016, 7, 12308. [CrossRef] [PubMed]

88. Kapur, A.; Beres, T.; Rathi, K.; Nayak, A.P.; Czarnecki, A.; Felder, M.; Gillette, A.; Ericksen, S.S.; Sampene, E.; Skala, M.C.; et al. Oxidative stress via inhibition of the mitochondrial electron transport and Nrf-2-mediated anti-oxidative response regulate the cytotoxic activity of plumbagin. Sci. Rep. 2018, 8, 1073. [CrossRef] [PubMed] 
89. Goncalves, R.L.; Quinlan, C.L.; Perevoshchikova, I.V.; Hey-Mogensen, M.; Brand, M.D. Sites of superoxide and hydrogen peroxide production by muscle mitochondria assessed ex vivo under conditions mimicking rest and exercise. J. Biol. Chem. 2015, 290, 209-227. [CrossRef] [PubMed]

90. Murphy, M.P. How mitochondria produce reactive oxygen species. Biochem. J. 2009, 417, 1-13. [CrossRef] [PubMed]

91. Bedard, K.; Krause, K.H. The NOX family of ROS-generating NADPH oxidases: Physiology and pathophysiology. Physiol. Rev. 2007, 87, 245-313. [CrossRef] [PubMed]

92. Chen, Y.; Azad, M.B.; Gibson, S.B. Superoxide is the major reactive oxygen species regulating autophagy. Cell Death Differ. 2009, 16, 1040-1052. [CrossRef] [PubMed]

93. Rhee, S.G. Cell signaling. $\mathrm{H}_{2} \mathrm{O}_{2}$, a necessary evil for cell signaling. Science 2006, 312, 1882-1883. [CrossRef] [PubMed]

94. Winterbourn, C.C.; Hampton, M.B. Thiol chemistry and specificity in redox signaling. Free Radic. Biol. Med. 2008, 45, 549-561. [CrossRef] [PubMed]

95. Dizdaroglu, M.; Jaruga, P. Mechanisms of free radical-induced damage to DNA. Free Radic. Res. 2012, 46, 382-419. [CrossRef] [PubMed]

96. Hafeez, B.B.; Zhong, W.; Mustafa, A.; Fischer, J.W.; Witkowsky, O.; Verma, A.K. Plumbagin inhibits prostate cancer development in TRAMP mice via targeting PKCepsilon, Stat 3 and neuroendocrine markers. Carcinogenesis 2012, 33, 2586-2592. [CrossRef] [PubMed]

97. Hafeez, B.B.; Fischer, J.W.; Singh, A.; Zhong, W.; Mustafa, A.; Meske, L.; Sheikhani, M.O.; Verma, A.K. Plumbagin Inhibits Prostate Carcinogenesis in Intact and Castrated PTEN Knockout Mice via Targeting PKCepsilon, Stat3, and Epithelial-to-Mesenchymal Transition Markers. Cancer Prev. Res. 2015, 8, 375-386. [CrossRef] [PubMed]

98. Srivastava, I.K.; Morrisey, J.M.; Darrouzet, E.; Daldal, F.; Vaidya, A.B. Resistance mutations reveal the atovaquone-binding domain of cytochrome $\mathrm{b}$ in malaria parasites. Mol. Microbiol. 1999, 33, 704-711. [CrossRef] [PubMed]

99. Plucinski, M.M.; Huber, C.S.; Akinyi, S.; Dalton, W.; Eschete, M.; Grady, K.; Silva-Flannery, L.; Mathison, B.A.; Udhayakumar, V.; Arguin, P.M.; et al. Novel Mutation in Cytochrome B of Plasmodium falciparum in One of Two Atovaquone-Proguanil Treatment Failures in Travelers Returning From Same Site in Nigeria. Open Forum Infect. Dis. 2014, 1, ofu059. [CrossRef] [PubMed]

100. Gil, J.P.; Nogueira, F.; Stromberg-Norklit, J.; Lindberg, J.; Carrolo, M.; Casimiro, C.; Lopes, D.; Arez, A.P.; Cravo, P.V.; Rosario, V.E. Detection of atovaquone and Malarone resistance conferring mutations in Plasmodium falciparum cytochrome b gene (cytb). Mol. Cell. Probes 2003, 17, 85-89. [CrossRef] 